\title{
Symptoms of Apathy Are Associated with Progression from Mild Cognitive Impairment to Alzheimer's Disease in Non-Depressed Subjects
}

\author{
E. Richard ${ }^{\mathrm{a}} \quad$ B. Schmand ${ }^{\mathrm{a}, \mathrm{c}} \quad$ P. Eikelenboom ${ }^{\mathrm{a}, \mathrm{d}} \quad$ S.C. Yang ${ }^{\mathrm{a}} \quad$ S.A. Ligthart ${ }^{\mathrm{b}}$ \\ E.P. Moll van Charante ${ }^{b}$ W.A. van Gool ${ }^{a}$ for the Alzheimer's Disease \\ Neuroimaging Initiative \\ Departments of ${ }^{\mathrm{N} N e u r o l o g y}$ and ${ }^{\mathrm{b}}$ General Practice, Academic Medical Centre, University of Amsterdam, \\ 'Department of Psychology, University of Amsterdam, and ${ }^{\mathrm{d} D e p a r t m e n t}$ of Psychiatry, VU University Medical \\ Centre, Amsterdam, The Netherlands
}

\section{Key Words}

Apathy · Depression • Mild cognitive impairment •

Alzheimer's disease $\cdot$ Dementia

\begin{abstract}
Background: Apathy is a common symptom in various neuropsychiatric diseases including mild cognitive impairment (MCl) and dementia. Apathy may be associated with an increased risk of cognitive decline. The objective of this study was to investigate if apathy predicts the progression from $\mathrm{MCl}$ to Alzheimer's disease (AD). Methods: The Alzheimer's Disease Neuroimaging Initiative is a prospective multicentre cohort study. At baseline, 397 patients with $\mathrm{MCl}$ without major depression were included. Clinical data and the Geriatric Depression Scale at baseline were used. Apathy was defined based on the 3 apathy items of the 15-item Geriatric Depression Scale. The main outcome measure was the association of apathy with progression from $\mathrm{MCI}$ to AD. Results: During an average follow-up of 2.7 years (SD 1.0), $166(41.8 \%)$ patients progressed to AD. The presence of symptoms of apathy without symptoms of depressive affect increased the risk of progression from $\mathrm{MCI}$ to $\mathrm{AD}$ (hazard ratio $=1.85,95 \% \mathrm{Cl}=1.09-3.15)$. Apathy in the context of symptoms of depressive affect or symptoms of depressive affect alone, without apathy, did not increase the risk of pro-
\end{abstract}

(C) 2012 S. Karger AG, Basel

$1420-8008 / 12 / 0333-0204 \$ 38.00 / 0$

Fax +41613061234

E-Mail karger@karger.ch

www.karger.com
Accessible online at: www.karger.com/dem gression to AD. Conclusions: Symptoms of apathy, but not symptoms of depressive affect, increase the risk of progression from $\mathrm{MCl}$ to $\mathrm{AD}$. Apathy in the context of symptoms of depressive affect does not increase this risk. Symptoms of apathy and depression have differential effects on cognitive decline.

Copyright $\odot 2012$ S. Karger AG, Basel

\section{Introduction}

Apathy is characterised by a lack of motivation and operationalised as diminished goal-oriented behaviour and cognition, but there is no consensus on the nosological position of apathy $[1,2]$. Recent consensus criteria on apathy have been published [3]. It is a common symptom in several neuropsychiatric diseases including dementia, stroke, Parkinson's disease and schizophrenia [4]. Although related to depression, apathy is a motivational disorder that can be distinguished from depression, which is characterised by feelings of sadness, hopelessness or inappropriate guilt $[1,5]$. Apathy may occur in the absence of depression in physically healthy elderly, and in patients with mild cognitive impairment (MCI) and dementia [6-8].

In patients with MCI and dementia, depressive symptoms are common $[8,9]$. In some studies, depression or 
depressive symptoms are associated with an increased risk of progression from MCI to dementia, but in other studies this could not be confirmed [8-11]. Apathy has also been described to increase the risk of progression from MCI to dementia $[8,10,12,13]$. In this study, we aim to assess whether symptoms of apathy in subjects without overt depression are associated with an increased risk of progression from MCI to Alzheimer's disease (AD). We hypothesised that symptoms of apathy, rather than symptoms of depressed affect, are associated with progression from $\mathrm{MCI}$ to $\mathrm{AD}$.

\section{Methods}

Data used for this study were obtained from the Alzheimer's Disease Neuroimaging Initiative (ADNI) database (www.loni. ucla.edu/ADNI; accessed June 18, 2011). As such, the investigators within the ADNI contributed to the design and implementation of ADNI and/or provided data but did not participate in the analysis or writing of this report. A complete listing of ADNI investigators is available at: http://www.loni.ucla.edu/ ADNI/Collaboration/ADNI_Manuscript_Citations.pdf.

The ADNI was launched in 2003 by the National Institute on Aging, the National Institute of Biomedical Imaging and Bioengineering, the Food and Drug Administration, private pharmaceutical companies and non-profit organisations to test whether different diagnostic instruments can be combined to measure the progression of MCI and early AD. With M.W. Weiner as Principal Investigator, ADNI has recruited subjects from over 50 sites across the USA and Canada. The goal was to recruit 800 adults - approximately 200 cognitively normal older individuals and 400 people with MCI to be followed for 3 years, and 200 people with early AD to be followed for 2 years (see also www.adni-info.org) [14].

\section{Subjects}

We included patients with MCI from the ADNI database. Patients were diagnosed as having MCI if they had subjective memory complaints corroborated by an informant and by an abnormal score on the delayed paragraph recall subtest of the Wechsler Memory Scale-Revised, a Mini Mental State Examination (MMSE) score $>23$, and a Clinical Dementia Rating Scale score of 0.5 , not satisfying consensus criteria for dementia, in line with current guidelines. Depression, defined as a score $\geq 6$ on the 15 -item Geriatric Depression Scale (GDS$15)$, was an exclusion criterion. All subjects with MCI and complete GDS at baseline were included in this study.

\section{Apathy and Depression Assessment}

Symptoms of apathy and depressive affect were assessed at baseline using the GDS-15. Within the GDS-15, there are 3 items that represent apathy/withdrawal, rather than dysphoria [(1) Have you dropped many of your activities? (2) Do you prefer to stay at home, rather than going out and doing new things? (3) Do you feel full of energy?] [15]. In a factor analysis of the GDS-15, these 3 items loaded on the same factor [16]. We recently confirmed this factor analysis of the GDS-15 in a cohort of 3,534 elderly, in which we also confirmed the clinical applicability of the GDS-3-apathy [17]. The test characteristics of this GDS-3-apathy have been shown to be good compared to the 14-item apathy scale of Starkstein, with a sensitivity of $69 \%$ and a specificity of $85 \%[16,18]$. The remaining items reflect general depressive affect and life satisfaction, which we will refer to as symptoms of depressive affect [15]. Since subjects with a GDS- 15 score $\geq 6$ were excluded from the ADNI study, few subjects scored positive on the maximum number of 3 apathy items. Therefore, we dichotomised the presence of symptoms of apathy and symptoms of depressive affect into any symptom versus no symptoms.

\section{Statistical Analysis}

The patients were divided into four groups: (1) no symptoms of apathy or depressive affect, (2) only symptoms of apathy, (3) only symptoms of depressive affect, and (4) symptoms of apathy and depressive affect.

Baseline characteristics were compared between groups using analysis of variance (ANOVA) and $\chi^{2}$ statistics where appropriate. Age was divided into quartiles and years of education into tertiles. The time to event variable was defined as the time from baseline to diagnosis in subjects who developed AD. Subjects who remained stable were right-censored at the time of last visit. Cox proportional hazards models were used to assess whether symptoms of apathy or depression increased the risk of progression to dementia. We used two models. Model 1 is unadjusted and model 2 is adjusted for age, education, gender and baseline MMSE score. The rationale for the adjusted model is that these covariates are potentially all associated with apathy, depressive affect and cognitive decline. Results in the text are from the adjusted model.

\section{Results}

There were 397 subjects with MCI at baseline. Patients with symptoms of apathy were slightly older than patients with symptoms of depressive affect only and there were no differences in education or MMSE score (table 1). One hundred and seventy-eight (44.8\%) patients had at least 1 symptom of apathy. Fifty-nine (14.8\%) patients had symptoms of apathy only and $127(32.0 \%)$ patients had symptoms of depressive affect only. An overview of symptom severity on the GDS-3-apathy and GDS-12depression can be found in table 2. Seventeen (4.3\%) patients had no follow-up visit. Demographics of these patients were similar. During an average follow-up of 2.7 years (SD 1.0, range 0.4-5.2), 166 (41.8\%) patients progressed to $\mathrm{AD}$. The presence of symptoms of apathy only at baseline was associated with an increased risk of progression to dementia during follow-up (hazard ratio $=$ 
Table 1. Baseline characteristics of subjects $(n=397)$

\begin{tabular}{llllll}
\hline & $\begin{array}{l}\text { No symptoms of } \\
\text { apathy or depressed } \\
\text { affect } \\
(\mathrm{n}=92)\end{array}$ & $\begin{array}{l}\text { Apathy symptoms } \\
\text { only } \\
(\mathrm{n}=59)\end{array}$ & $\begin{array}{l}\text { Symptoms of } \\
\text { depressed affect only } \\
(\mathrm{n}=127)\end{array}$ & $\begin{array}{l}\text { Symptoms of both } \\
\text { apathy and depressed } \\
\text { affect } \\
(\mathrm{n}=119)\end{array}$ & $\mathrm{p}$ \\
\hline Age, mean \pm SD, years & $75.9 \pm 6.6$ & $77.5 \pm 7.2$ & $72.8 \pm 7.5$ & $74.7 \pm 7.7$ & 0.001 \\
Male, \% & 64.1 & 64.4 & 63.0 & 66.4 & 0.96 \\
Education, mean $\pm \mathrm{SD}$, years & $15.7 \pm 3.0$ & $15.6 \pm 2.8$ & $15.8 \pm 3.0$ & $15.6 \pm 3.2$ & 0.94 \\
MMSE score, mean \pm SD & $27.0 \pm 1.8$ & $27.3 \pm 1.7$ & $27.0 \pm 1.8$ & $26.9 \pm 1.8$ & 0.50 \\
\hline
\end{tabular}

Table 2. Severity of symptoms of apathy and depression

\begin{tabular}{lrcc}
\hline Score & GDS-15 & GDS-12-depression & GDS-3-apathy \\
\hline 0 & $92(23 \%)$ & $151(38 \%)$ & $219(55 \%)$ \\
1 & $135(34 \%)$ & $159(40 \%)$ & $127(32 \%)$ \\
2 & $79(20 \%)$ & $49(12 \%)$ & $41(10 \%)$ \\
3 & $49(12 \%)$ & $23(6 \%)$ & $10(3 \%)$ \\
4 & $23(6 \%)$ & $13(3 \%)$ & - \\
5 & $19(5 \%)$ & $2(1 \%)$ & -
\end{tabular}

Number of items positively scored on the GDS-15, GDS12-depression and the GDS-3-apathy.

$1.85,95 \% \mathrm{CI}=1.09-3.15$ ) (table 3; fig. 1). An additional analysis on patients with only symptoms of apathy and a GDS-3-apathy score $\geq 2(\mathrm{n}=19)$ yielded comparable results, although not significant, probably due to the small sample size (hazard ratio $=2.06,95 \%$ CI $=0.92-4.62$ ) . The presence of symptoms of depressive affect alone, without apathy, was not associated with an increased risk of progression to $\mathrm{AD}$ (hazard ratio $=1.15,95 \% \mathrm{CI}$ $=0.72-1.83)$. An additional analysis on patients with a GDS-12 score $\geq 2$ did not change these results (hazard ratio $=0.55,95 \% \mathrm{CI}=0.24-1.35)$. The combination of symptoms of both apathy and depressive affect was not associated either with an increased risk of progression to dementia compared to subjects with no symptoms of depressive affect or apathy (hazard ratio $=1.05,95 \% \mathrm{CI}=$ $0.91-1.23)$.

\section{Discussion}

Our finding that symptoms of apathy, but not symptoms of depressive affect, are associated with progression from $\mathrm{MCI}$ to $\mathrm{AD}$ illustrate that these symptoms can have a differential impact on cognitive function, as was

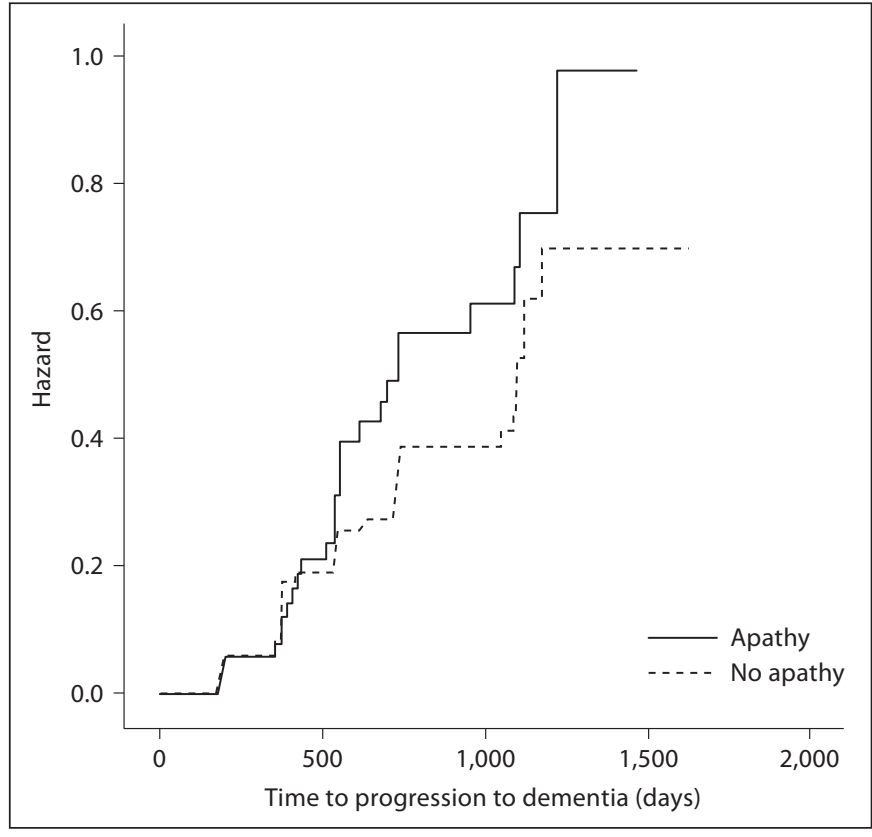

Fig. 1. Hazard for progression from MCI to dementia during follow-up for patients with no symptoms of depression at baseline. The continuous line depicts patients with symptoms of apathy and the dashed line depicts patients with no apathy at baseline.

previously described $[8,12]$. We have shown that apathy without symptoms of depressive affect increases the risk of progression to $\mathrm{AD}$, but apathy in the context of symptoms of depressive affect does not, confirming the relevance of apathy as a separate construct in MCI and early AD [19]. We have illustrated that even in patients with no signs of overt depression (GDS-15 score $<6$ ), the presence of symptoms of apathy is a predictor of progression from MCI to $\mathrm{AD}$.

The mechanisms underlying the association between apathy and dementia or progression from MCI to dementia have not been elucidated. It could be a true causal risk 
Table 3. Risk of progression from MCI to dementia

\begin{tabular}{llll}
\hline & $\begin{array}{l}\text { Progression to } \\
\text { dementia, } \mathrm{n}\end{array}$ & $\begin{array}{l}\text { Model 1 } \\
\text { HR (95\% CI) }\end{array}$ & $\begin{array}{l}\text { Model 2 } \\
\text { HR (95\% CI) }\end{array}$ \\
\hline $\begin{array}{l}\text { Patients with no symptoms of depression }(\mathrm{n}=151) \\
\text { No apathy symptoms }(\mathrm{n}=92)\end{array}$ & 35 & 1 & 1 \\
$\begin{array}{l}\text { Apathy symptoms }(\mathrm{n}=59) \\
\text { Patients with no symptoms of apathy }(\mathrm{n}=219)\end{array}$ & 27 & $1.43(0.86-2.38)$ & $1.85(1.09-3.15)$ \\
$\begin{array}{l}\text { No depression symptoms }(\mathrm{n}=92) \\
\text { Depression symptoms }(\mathrm{n}=127)\end{array}$ & 35 & 1 & 1 \\
\hline $\begin{array}{l}\text { Patients with symptoms of apathy and depression or no symptoms at all }(n=211) \\
\text { No apathy or depression symptoms }(\mathrm{n}=92)\end{array}$ & 35 & 1 & $1.15(0.72-1.83)$ \\
Apathy and depression symptoms $(\mathrm{n}=119)$ & 55 & $1.10(0.95-1.27)$ & $1.05(0.91-1.23)$ \\
\hline
\end{tabular}

Hazard ratios (95\% CI) for progression from MCI to dementia for patients with symptoms of apathy, symptoms of depression, or symptoms of both apathy and depression. Model 1 is unadjusted, model 2 is adjusted for age, gender, education and baseline MMSE score. $\mathrm{HR}=$ Hazard ratio.

factor, a symptom of the underlying neurodegenerative disease, a reaction to cognitive impairment or based on a shared risk factor. Our finding, consistent with previous findings, that symptoms of apathy but not symptoms of depressive affect are associated with an increased risk of progression from MCI to dementia suggests that different pathophysiological mechanisms underlie apathy and depression in MCI and dementia. Our data also suggest that when symptoms of apathy occur together with symptoms of depressive affect, the impact on cognitive decline is different. A potential explanation could be that apathy in the absence of depressive affect is stronger related to the presence of cerebrovascular disease, as we have recently shown in a very large cohort of elderly subjects [17].

Because ADNI was not designed to address this specific question, the available apathy measure was limited to the 3 apathy items of the GDS-15. Although this is a limitation of our study, this instrument has been shown to have good discriminating characteristics compared to the apathy scale of Starkstein $[16,18]$. In addition, Robert et al. [20] emphasise that 'lack of interest' is the apathy dimension most associated with progression to $A D$, and 2 of the 3 apathy items in the GDS represent this same dimension. Our recent analysis in a cohort of 3,534 community-dwelling elderly, including a confirmatory factor analysis, supports the clinical applicability of the GDS-3-apathy [17]. By dichotomising apathy into any versus no symptoms, we employed a very sensitive way of assessing symptoms of apathy. This resulted in the presence of symptoms of apathy in $44.8 \%$ (14.9\% with apathy only) of the patients, which is only slightly higher than in most clinic-based MCI cohorts using instruments specifically designed to assess apathy, which report a prevalence between 25 and 40\% [20-22]. Previously, Teng et al. [13] also reported an association between apathy and risk of progression to $\mathrm{MCI}$ in a small sample, with very low scores on the apathy item of the Neuropsychiatric Inventory. Because the test characteristics of the GDS-3apathy were previously reported using a cut-off of 2 , we did an additional analysis using this cut-off, confirming the validity of our very sensitive cut-off of the GDS-3apathy in this cohort of patients with no overt depression (GDS-15 score $<6$ ).

It is important to notice that our findings come from a selected clinic-based cohort, so cannot readily be translated to other populations. Patients suffering from a major depression were most likely excluded, because a GDS- 15 score $\geq 6$ was an exclusion criterion in ADNI. The exclusion of patients with a major depression on the other hand has led to an MCI population in which it is unlikely that affective symptoms are causally related to the cognitive impairment. It is remarkable that even in this population without an overt affective disorder, we have shown that symptoms of apathy are associated with an increased risk of progression to dementia.

Strengths of our study are that compared to most previous studies $[10,16,18]$ the ADNI population concerns a large sample size $(\mathrm{n}=397)$ with a high number of patients progressing to dementia $(n=166)$ due to the long follow-up. 
Our findings illustrate that even low-grade presence of symptoms of apathy in MCI patients without an overt affective disorder at a memory clinic should be recognised. This could prompt closer monitoring of cognitive decline in order to detect clinically relevant decline and anticipate the required extra care. The differential impact of symptoms of apathy and symptoms of depressive affect on cognitive decline suggest that different treatments might be indicated.

Apathy without symptoms of depressive affect is a separate construct and is associated with an increased risk of progression from MCI to dementia. Symptoms of apathy in the context of symptoms of depressive affect or symptoms of depressive affect alone do not increase this risk.

\section{Acknowledgements}

Data collection and sharing for this project was funded by the Alzheimer's Disease Neuroimaging Initiative (ADNI) (National Institutes of Health Grant U01 AG024904). ADNI is funded by the National Institute on Aging, the National Institute of Biomedical Imaging and Bioengineering, and through generous contributions from the following: Abbott,
AstraZeneca AB, Bayer Schering Pharma AG, Bristol-Myers Squibb, Eisai Global Clinical Development, Elan Corporation, Genentech, GE Healthcare, GlaxoSmithKline, Innogenetics, Johnson and Johnson, Eli Lilly and Co., Medpace Inc., Merck and Co. Inc., Novartis AG, Pfizer Inc., F. Hoffman-La Roche, Schering-Plough, Synarc Inc., as well as non-profit partners the Alzheimer's Association and Alzheimer's Drug Discovery Foundation, with participation from the US Food and Drug Administration. Private sector contributions to ADNI are facilitated by the Foundation for the National Institutes of Health (www.fnih.org). The grantee organization is the Northern California Institute for Research and Education, and the study is coordinated by the Alzheimer's Disease Cooperative Study at the University of California, San Diego. ADNI data are disseminated by the Laboratory for Neuro Imaging at the University of California, Los Angeles. This research was also supported by NIH grants P30 AG010129, K01 AG030514, and the Dana Foundation.

\section{Disclosure Statement}

None of the authors reports a conflict of interest. No specific funding was obtained for the preparation of this manuscript. Dr. Richard receives funding from the Alzheimer's Association (NIRG-10-173212).

\section{References}

1 Starkstein SE, Leentjens AF: The nosological position of apathy in clinical practice. J Neurol Neurosurg Psychiatry 2008;79:1088-1092.

$>2$ Marin RS: Apathy: a neuropsychiatric syndrome. J Neuropsychiatry Clin Neurosci 1991;3:243-254.

3 Robert P, Onyike CU, Leentjens AF, Dujardin K, Aalten P, Starkstein S, Verhey FR, Yessavage J, Clement JP, Drapier D, Bayle F, Benoit M, Boyer P, Lorca PM, Thibaut F, Gauthier S, Grossberg G, Vellas B, Byrne J: Proposed diagnostic criteria for apathy in Alzheimer's disease and other neuropsychiatric disorders. Eur Psychiatry 2009;24: 98-104.

4 van RR, Stuss DT, Ostrander L: Apathy: why care? J Neuropsychiatry Clin Neurosci 2005; 17:7-19.

5 Clarke DE, Ko JY, Kuhl EA, van RR, Salvador R, Marin RS: Are the available apathy measures reliable and valid? A review of the psychometric evidence. J Psychosom Res 2011; 70:73-97.

-6 Brodaty H, Altendorf A, Withall A, Sachdev P: Do people become more apathetic as they grow older? A longitudinal study in healthy individuals. Int Psychogeriatr 2010;22: 426-436.
7 Levy ML, Cummings JL, Fairbanks LA, Masterman D, Miller BL, Craig AH, Paulsen JS, Litvan I: Apathy is not depression. J Neuropsychiatry Clin Neurosci 1998;10:314-319.

-8 Palmer K, Di IF, Varsi AE, Gianni W, Sancesario G, Caltagirone C, Spalletta G: Neuropsychiatric predictors of progression from amnestic-mild cognitive impairment to $\mathrm{Al}$ zheimer's disease: the role of depression and apathy. J Alzheimers Dis 2010;20:175-183.

-9 Modrego PJ, Ferrandez J: Depression in patients with mild cognitive impairment increases the risk of developing dementia of Alzheimer type: a prospective cohort study. Arch Neurol 2004;61:1290-1293.

10 Robert PH, Berr C, Volteau M, Bertogliati C, Benoit M, Sarazin M, Legrain S, Dubois B: Apathy in patients with mild cognitive impairment and the risk of developing dementia of Alzheimer's disease: a one-year follow-up study. Clin Neurol Neurosurg 2006; 108:733-736.

11 Rozzini L, Chilovi BV, Trabucchi M, Padovani A: Depression is unrelated to conversion to dementia in patients with mild cognitive impairment. Arch Neurol 2005;62: 505-506.
12 Vicini CB, Conti M, Zanetti M, Mazzu I, Rozzini L, Padovani A: Differential impact of apathy and depression in the development of dementia in mild cognitive impairment patients. Dement Geriatr Cogn Disord 2009;27:390-398.

13 Teng E, Lu PH, Cummings JL: Neuropsychiatric symptoms are associated with progression from mild cognitive impairment to Alzheimer's disease. Dement Geriatr Cogn Disord 2007;24:253-259.

14 Weiner MW, Aisen PS, Jack CR Jr, Jagust WJ, Trojanowski JQ, Shaw L, Saykin AJ, Morris JC, Cairns N, Beckett LA, Toga A, Green R, Walter S, Soares H, Snyder P, Siemers E, Potter W, Cole PE, Schmidt M: The Alzheimer's disease neuroimaging initiative: progress report and future plans. Alzheimers Dement 2010;6:202-211.

15 Mitchell J, Mathews HF, Yesavage JA: A multidimensional examination of depression among the elderly. Res Aging 1993;15: 198-219.

16 van der Mast RC, Vinkers DJ, Stek ML, Bek MC, Westendorp RG, Gussekloo J, de Craen AJ: Vascular disease and apathy in old age. The Leiden 85-Plus Study. Int J Geriatr Psychiatry 2008;23:266-271. 
17 Ligthart SA, Richard E, Fransen N, Eurelings LS, Beem L, Eikelenboom P, van Gool WA, Moll van Charante EP: Vascular factors are associated with apathy in community-dwelling elderly. Arch Gen Psychiatry 2012;69:1-7.

- 18 Starkstein SE, Mayberg HS, Preziosi TJ, Andrezejewski P, Leiguarda R, Robinson RG: Reliability, validity, and clinical correlates of apathy in Parkinson's disease. J Neuropsychiatry Clin Neurosci 1992;4:134-139.
19 Starkstein SE, Petracca G, Chemerinski E, Kremer J: Syndromic validity of apathy in Alzheimer's disease. Am J Psychiatry 2001; 158:872-877.

20 Robert PH, Berr C, Volteau M, BertogliatiFileau C, Benoit M, Guerin O, Sarazin M, Legrain S, Dubois B: Importance of lack of interest in patients with mild cognitive impairment. Am J Geriatr Psychiatry 2008;16: 770-776.
21 Apostolova LG, Cummings JL: Neuropsychiatric manifestations in mild cognitive impairment: a systematic review of the literature. Dement Geriatr Cogn Disord 2008;25: 115-126.

22 Duara R, Loewenstein DA, Greig MT, Potter E, Barker W, Raj A, Schinka J, Borenstein A, Schoenberg M, Wu Y, Banko J, Potter H: Pre-MCI and MCI: neuropsychological, clinical, and imaging features and progression rates. Am J Geriatr Psychiatry 2011;19: 951-960. 